\title{
Debris flows in the eastern Italian Alps: seasonality and atmospheric circulation patterns
}

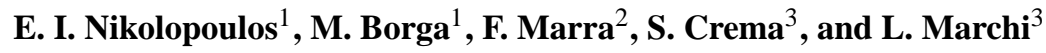 \\ ${ }^{1}$ Department of Land, Environment, Agriculture and Forestry, University of Padova, Padova, Legnaro, Italy \\ ${ }^{2}$ Department of Geography, Hebrew University of Jerusalem, Jerusalem, Israel \\ ${ }^{3}$ National Research Council of Italy, Research Institute for Geo-hydrological Protection, Padova, Italy \\ Correspondence to: E. I. Nikolopoulos (efthymios.nikolopoulos@unipd.it)
}

Received: 29 September 2014 - Published in Nat. Hazards Earth Syst. Sci. Discuss.: 1 December 2014

Revised: 17 February 2015 - Accepted: 8 March 2015 - Published: 27 March 2015

\begin{abstract}
The work examines the seasonality and large-scale atmospheric circulation patterns associated with debris-flow occurrence in the Trentino-Alto Adige region (eastern Italian Alps). Analysis is based on classification algorithms applied to a uniquely dense archive of debris flows and hourly rain gauge precipitation series covering the period 2000-2009. Results highlight the seasonal and synoptic forcing patterns linked to debris flows in the study area. Summer and fall season account for $92 \%$ of the debris flows in the record, while atmospheric circulation characterized by zonal west, mixed and meridional south and southeast (SE-S) patterns account for $80 \%$. Both seasonal and circulation patterns exhibit geographical preference. In the case of seasonality, there is a strong north-south separation of summer-fall dominance, while spatial distribution of dominant circulation patterns exhibits clustering, with both zonal west and mixed patterns prevailing in the northwest and central east part of the region, while the southern part relates to meridional south and southeast pattern. Seasonal and synoptic pattern dependence is pronounced also on the debris-flow-triggering rainfall properties. Examination of rainfall intensity-duration thresholds derived for different data classes (according to season and synoptic pattern) revealed a distinct variability in estimated thresholds. These findings imply a certain control on debrisflow events and can therefore be used to improve existing alert systems.
\end{abstract}

\section{Introduction}

Debris flows are recognized as one of the most devastating natural disasters for mountainous regions at global scale (Dowling and Santi, 2014). The sudden occurrence combined with the high destructive power of debris flows pose a significant threat to human life and infrastructures (Petley, 2012). Therefore, developing early warning procedures for the mitigation of debris-flow risk is of great economical and societal importance.

Effective debris-flow warning procedures require accurate knowledge on the relevant triggering mechanisms and their corresponding characteristics (Borga et al., 2014). Indisputably, rainfall is the predominant factor controlling debrisflow triggering. Hence, most of the work so far on the prediction of debris-flow occurrence is focused on the identification of relevant rainfall conditions (Guzzetti et al., 2008 and references therein; Nikolopoulos et al., 2014; Segoni et al., 2014). However, the vast majority of the literature on identification of debris-flow-triggering rainfall conditions deals primarily with the estimation of rainfall properties (e.g. rainfall duration, intensity or accumulation) leading to debris flows. Less attention has been paid to the seasonal and meteorological characteristics of the triggering rainfall events. Knowledge on the seasonality and meteorological patterns characterizing debris-flow-triggering rainfall events is important for two main reasons. First, classification of debris-flow events according to these factors may be used for the development of a typology for debris-flow rainfall events. This typology can subsequently be used for refining the rainfall triggering conditions according to different debris-flow types and 
thus improve prediction. This hypothesis was examined by Govi et al. (1985) who analyzed the seasonality effect on the triggering of shallow landslides (soil slip - mud flow and soil slip - debris flow) in a sector of NW Italy. It is also justified from the recent works of Peruccacci et al. (2012) and Vennari et al. (2014) who demonstrated differences in debris-flow-triggering rainfall properties between warm and cold season for central and southern Italy, respectively. Furthermore, Toreti et al. (2013) showed that debris-flow occurrence in the southern Swiss Alps, exhibits a distinct pattern in large-scale atmospheric circulation and suggested that this information can be used to improve existing warning systems. On this line, Turkington et al. (2014), in a study centered on the southern French Alps, showed that empirical thresholds can be directly identified based on regional atmospheric patterns. Second, linking debris-flow occurrence with seasonal and meteorological characteristics may provide indications on the potential impact of climate change on debris-flow activity (Stoffel et al., 2014). As an example, Schneuwly-Bollschweiler and Stoffel (2012) concluded that the observed seasonal shift in debris-flow activity in the Zermatt valley (Switzerland) is attributed to changes in precipitation and temperature regime in the Swiss Alps over the last century.

The main objective of this work is to investigate the existence of distinct patterns in seasonality and large-scale atmospheric circulation associated with rainfall events that trigger debris flows. Furthermore, examination of debris-flow rainfall properties with respect to seasonality and weather circulation patterns is investigated to evaluate the potential benefit of using such discriminant factors for the identification of debris-flow-triggering rainfall conditions. The work is focused over the Trentino-Alto Adige region in the eastern Italian Alps, and the analysis is based on a 10-year record of debris-flow and raingauge-rainfall observations. Section 2 provides a description of the study area and the different data sources used in the analysis. Results from the analysis are presented and discussed in Sect. 3. The main conclusions derived from this work are summarized in Sect. 4.

\section{Study area and data}

\subsection{The Trentino-Alto Adige region}

The Trentino-Alto Adige study region is located in the eastern Italian Alps (Fig. 1); it covers $13607 \mathrm{~km}^{2}$ and is characterized by complex topography with an elevation ranging from 65 to almost $4000 \mathrm{~m}$ a.s.l. (mean elevation is approximately $1600 \mathrm{~m}$ a.s.l.). Mean annual precipitation amounts exhibit strong spatial variability in the region, with annual sums of slightly above $500 \mathrm{~mm}$ in the northwestern portion of the region (the Venosta Valley, located in the rain-shaded Inner Alps) and exceeding $1500 \mathrm{~mm}$ in the southeastern edge of the area. The features of the precipitation mean annual

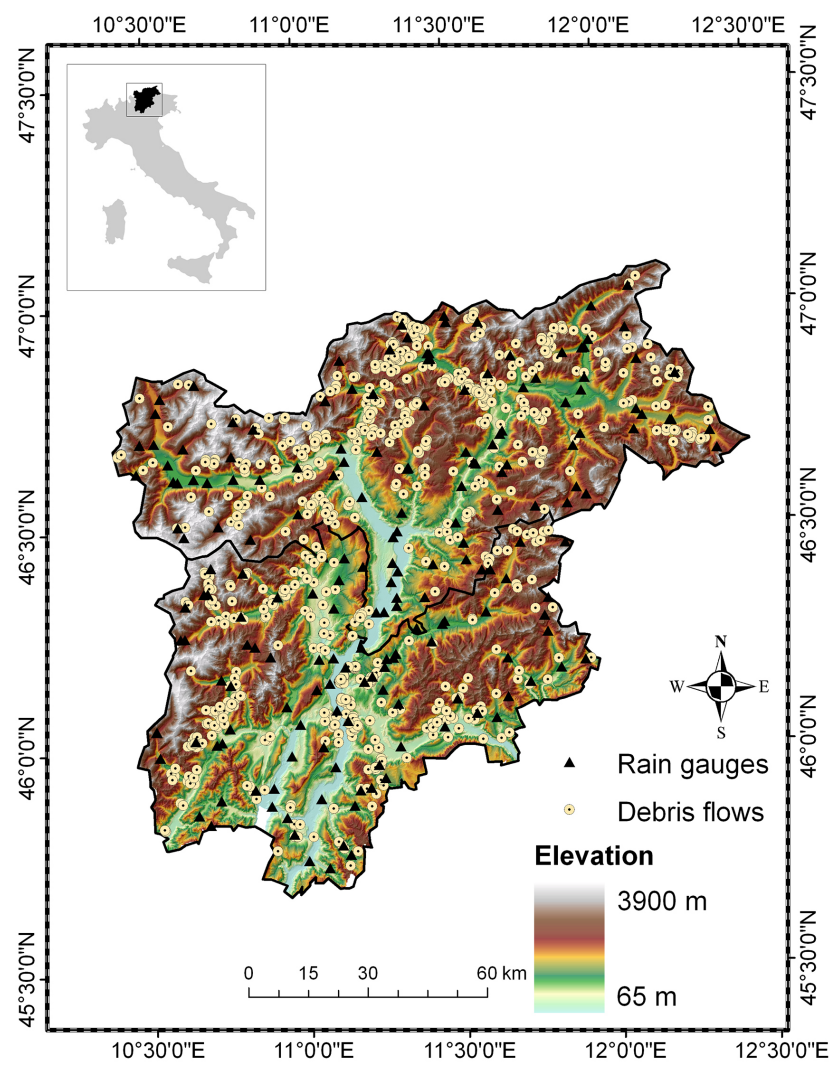

Figure 1. Map of the Trentino-Alto Adige region. Shades of color show terrain elevation. Triangles and circles show respectively the location of rain gauges and debris flows involved in current study.

climatology exhibit characteristic seasonal variations (Norbiato et al., 2009; Parajka et al., 2010). The precipitation regime in the northern part of the study area is characterized as continental, with a unimodal cycle and the highest precipitation amount during the main convective period (MaySeptember). The southern portion of the study area exhibits a bimodal regime, with maxima in spring-early summer and in autumn, which generally receives the most abundant precipitation. Typically the precipitation during cold months (October-April) is in the form of snow and widespread precipitation while mesoscale convective systems and localized thunderstorms dominate the precipitation regime during warm months (May-September) (Norbiato et al., 2009; Mei et al., 2014).

There are two important factors that make the area attractive for this study. First, the region is characterized by significant societal risk due to both the high frequency and the impact (in terms of casualties) of landslides in the area (Salvati et al., 2010). Second, the availability of a long-term record of precipitation and debris flows (Nikolopoulos et al., 2014), as described in detail in the following section. 


\subsection{Debris flow and rainfall database}

Ten years (2000-2009) of available precipitation observations and debris flow (DF, hereinafter) records are analyzed in this work. Compilation of the DF events occurred in the region during the period 2000-2009 was based on two independent databases, covering the two administrative units: Trentino (377 events) and Alto Adige (444 events). The selected 821 were identified based on a larger number of events in order to get the same level of spatial and temporal occurrence accuracy. Available information includes the location of the individual DF initiation point (shown in Fig. 1) with a $500 \mathrm{~m}$ spatial accuracy and the date of occurrence with a daily accuracy. Hourly accumulation values of precipitation are obtained from a network of 192 rain gauges that cover the study region (Fig. 1). As can be seen from Fig. 1, rain gauge stations are spread quite uniformly over the region providing a spatial density approximately equal to $1 / 80$ (station per $\mathrm{km}^{2}$ ). The average (standard deviation, SD) of Euclidian distance and absolute altitudinal difference between debris flows and closest available rain gauge is $3.7(1.9) \mathrm{km}$ and $0.43(0.41) \mathrm{km}$ respectively.

\subsection{Weather circulation patterns}

The Hess and Brezowsky Grosswetterlagen (GWL) classification system (Hess and Brezowsky, 1952, 1969, 1977) is used for the classification of large scale atmospheric flow and weather circulation patterns. The GWL classification system is based on the mean air pressure distribution (sea level and $500 \mathrm{hPa}$ level) over the North Atlantic Ocean and Europe. The classification initially identifies three groups of circulation types (zonal, mixed and meridional), which are divided into 5 major types, which in turn are divided into 29 subtypes (Grosswetterlagen, GWL; Gestengabe and Werner, 2005; James, 2007). This classification system is frequently used to characterize the atmospheric flow and weather patterns over the eastern North Atlantic and Europe (Gestengarbe and Werner, 2005; Kysely and Huth, 2006; Planchon et al., 2009). Following Gestengabe and Werner (2005) and Parajka et al. (2010), the original GWL classes were further grouped into six categories (Table 1) that were used for the description of the general weather regime during DF events. For more detailed information on the GWL classification system and the individual GWL weather types, the interested reader is referred to Gestengabe and Werner (2005) and James (2007) and references therein.

The monthly frequency of the GWL groups (Table 1) is presented in Fig. 2, for the whole study period (2000-2009). As it is shown, the occurrence of a mixed weather pattern dominates the other patterns consistently over all months, with monthly occurrence being greater than $30 \%$ in all cases. On the other hand, the mixed CE type is associated with the minimum occurrence (less than $5 \%$ for all months except $\sim 10 \%$ in August), while the frequency for the rest of the

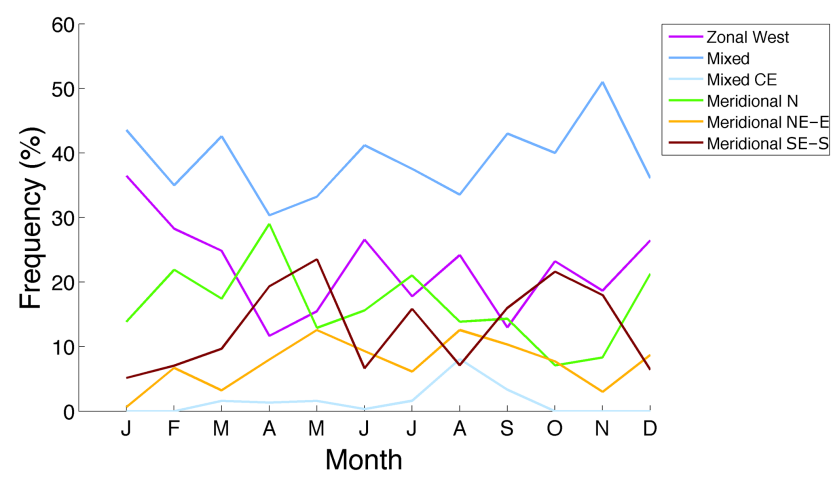

Figure 2. Frequency of occurrence of weather circulation patterns classified in the Groswetterlagen catalogue in the period 20002009.

weather patterns is within the same range and generally between 10 and $20 \%$. One noticeable feature is that during the winter period, apart from the mixed type, the zonal west pattern occurrence is significant and distinctly higher than the rest.

\section{Analysis and results}

\subsection{Spatial distribution of debris-flow-triggering rainfall properties}

Characteristic properties, namely duration and accumulation, for each DF-triggering rainfall event are estimated from the closest available rain gauge. Calculation of event-based properties is based on the identification of individual events in the rainfall records by separating subsequent rainfall events according to an inter-event period of 24 consecutive hours without rainfall (Nikolopoulos et al., 2014). This procedure results in the identification of a total of 128 individual rainfall events, which have triggered the $821 \mathrm{DF}$ analyzed here. To examine the spatial distribution of DF rainfall properties, results are grouped into different classes of duration and accumulation, respectively, and are mapped over the study region (Fig. 3). Geographical distribution of the DF rainfall properties, as shown in Fig. 3, allow us to investigate and potentially identify areas over the study region with distinct pattern in the characteristics of the triggering rainfall. In terms of duration, DF occurrence is dominated by events with duration $>24 \mathrm{~h}$, which account for $\sim 82 \%$ of the DF occurrences, while in terms of rainfall accumulation DF events are distributed more uniformly with 25-30\% of cases corresponding to each of the three highest classes $(>100,50-100$ and $20-50 \mathrm{~mm})$ and $\sim 14 \%$ for the lowest class $(<20 \mathrm{~mm})$. Visual interpretation of the spatial pattern of rainfall properties (Fig. 3) shows that classes of rainfall and duration are rather mixed without revealing geographic clustering of specific rainfall properties, apart from the northwestern part which is generally associated with relatively low $(<50 \mathrm{~mm})$ rain- 
Table 1. Groups of weather circulation pattern according to Grosswetterlagen classification scheme.

\begin{tabular}{ll}
\hline GWL group & GWL type (see Gestengabe and Werner, 2005) \\
\hline Zonal west & WA, WZ, WS, WW \\
Mixed & SWA, SWZ, NWA, NWZ, HM, BM \\
Mixed Central Europe (CE) & TM \\
Meridional north (N) & NA, NZ, HNA, HNZ, HB, TRM \\
Meridional northeast and east (NE-E) & NEA, NEZ, HFA, HFZ, HNFA, HNFZ \\
Meridional southeast and south (SE-E) & SEA, SEZ, SA, SZ, TB, TRW \\
\hline
\end{tabular}
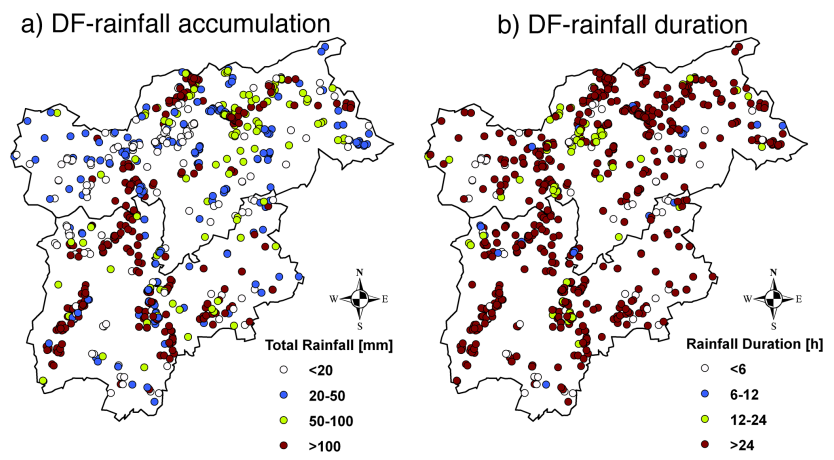

Figure 3. Map showing spatial distribution of DF rainfall (a) accumulation and (b) duration.

fall accumulation. However, one can notice that organization of high rainfall/duration events follows at a certain degree the shape of the principal mountainous ridges (see Fig. 1), which suggests the important role of orography in shaping the observed spatial patterns. Another important note, given that the analysis is conditioned to DF-triggering events, is that variability of the observed triggering rainfall properties may reflect also the spatial variability of other factors controlling DF triggering (e.g. topography, lithology, antecedent soil moisture conditions, etc).

\subsection{Seasonality of DF events}

Relationship between DF events and season is examined to analyze the importance of seasonality in (a) the occurrence of DF events and (b) the corresponding DF rainfall properties. Geographical distribution of the season of occurrence of the DF events is shown in Fig. 4a, which reveals two important features. First, summer and fall season dominate DF occurrence in the region of study. Specifically, $49 \%$ of the DF occurred during summer and $43 \%$ during the fall season (see Table 2 for more details). Second, there is a very distinct geographical separation between the two dominant seasons of DF occurrence. DFs in the northern part of the area are mainly occurring during the summer while at the southern part, DFs occur predominantly during the fall season. In addition, examining the seasonal distribution of DF rainfall events (Table 2) shows that summer season is asso-

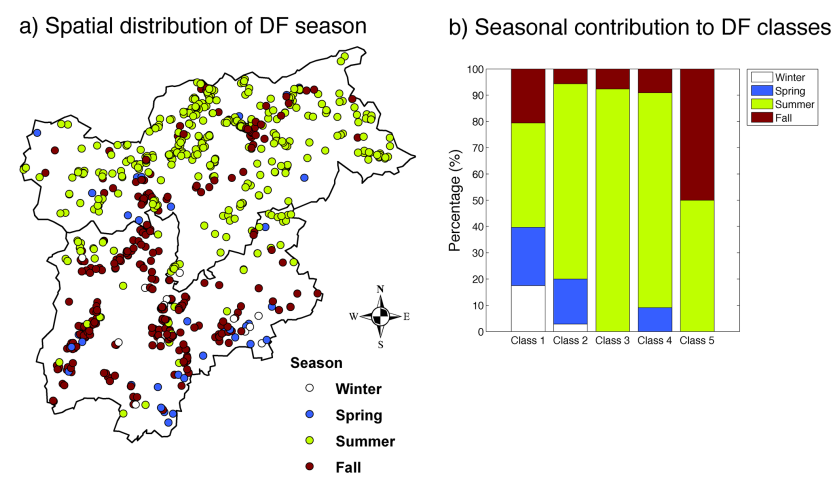

Figure 4. Seasonality of DF occurrence: (a) map showing spatial distribution of DF locations color coded according to season of occurrence, (b) correspondence between season and percentage of DF rainfall events, classified according to number of triggered DF. See Sect. 3.2 for definition of classes.

ciated with $59 \%$ of the rainfall events while spring and fall seasons correspond almost equally to $16 \%$ each and winter to $\sim 9 \%$. Relating the seasonal distribution of the number of rainfall events with that of DF occurrences indicates clearly that rainfall events during fall season are associated with the highest (on average) DF numbers per event. Specifically, the ratio $\mathrm{DF}$ / event is 1.25 (winter), 2.2 (spring), 5.4 (summer) and 17.75 (fall).

To further investigate the relationship between seasonality and number of DFs triggered per rainfall event, we classified DF rainfall events according to the total number of DFs triggered and analyzed the seasonal distribution of each class. Five classes were considered that included rainfall events with total DF triggered: 1 (class 1,63 events), $1<\mathrm{DF} \leq$ 5 (class 2, 35 events), $5<\mathrm{DF} \leq 10$ (class 3,13 events), $10<\mathrm{DF} \leq 20$ (class 4, 11 events) and DF $>20$ (class 5, 6 events). Examination of the results (Fig. 4b) shows that summer is clearly the dominant season in all classes. This is not surprising given that the greatest number of rainfall events is also associated with the summer season. For the first class that involved events with only $1 \mathrm{DF}$ occurrence, $60 \%$ of occurrences is almost uniformly distributed among winter, spring and fall and the rest $\sim 40 \%$ corresponds to summer. There are no winter events for classes higher than class 2 , suggesting that all winter events are associated with 
Table 2. Number of debris flows and individual rainfall events per season and weather type group. Results are reported also as percentages in the parenthesis.

\begin{tabular}{lrr} 
Season & $\begin{array}{r}\text { Number of DF } \\
\text { (total }=821)\end{array}$ & $\begin{array}{r}\text { Number of rainfall events } \\
\text { total }=128)\end{array}$ \\
\hline Winter & $15(2 \%)$ & $12(9 \%)$ \\
Spring & $46(6 \%)$ & $21(16 \%)$ \\
Summer & $405(49 \%)$ & $75(59 \%)$ \\
Fall & $355(43 \%)$ & $20(16 \%)$ \\
\hline \multicolumn{3}{c}{ GWL group } \\
\hline Zonal west & $95(12 \%)$ & $30(23 \%)$ \\
Mixed & $179(22 \%)$ & $44(34 \%)$ \\
CE & $7(1 \%)$ & $4(3 \%)$ \\
N & $86(10 \%)$ & $14(12 \%)$ \\
NE, E & $55(7 \%)$ & $9(7 \%)$ \\
SE, E & $399(49 \%)$ & $27(21 \%)$ \\
\hline
\end{tabular}

low number of DF occurrence. On the contrary, spring events are apparent for class 4, suggesting that spring events can be associated with the triggering of several DFs. Interestingly, the highest class $(\mathrm{DF}>20)$ is equally distributed between summer and fall season. Occurrence of a large number of DFtriggering rainfall events during summer is hypothesized as a result of mesoscale convective systems that although they have a relatively limited spatial extent, they are usually associated high intensities. On the other hand, rainfall events during fall season are commonly widespread systems covering a large spatial extent and are associated with moderate intensities but long durations and rather wet antecedent soil moisture conditions.

To examine the connection between rainfall climatology and DF seasonal spatial patterns observed in the region, we present in Figure 5 the mean annual rainfall map (Fig. 5a) and a comparison of the contribution of summer and fall season (Fig. 5b), during the study period. As shown in Fig. 5a, southern part receives most of rainfall $(\sim 1000-1300 \mathrm{~mm})$, northeastern part receives $\sim 600-900 \mathrm{~mm}$ while the northwestern part of the region receives significantly less rainfall ( $\sim 500 \mathrm{~mm}$ ), as a result of the shadowing effect posed by the mountainous range surrounding the area. Looking at the relative importance on the annual rainfall of summer versus fall season (Fig. 5b), it is clear that rainfall in the northeastern part is dominated by summer season, which is twice or more the fall season rainfall and accounts overall for $\sim 50 \%$ of annual rainfall (results not shown). Therefore dominance of summer season in DF occurrence in this part of the region reflects in essence the overall dominance of summer season in rainfall climatology. However, results for the southern part are interestingly different in the sense that in this case, the contribution of summer and fall is almost equal (i.e., ratio close to 1) and account for $\sim 30 \%$ (results not shown) of annual rainfall. This means that the "preference" of DF to occur a) Average annual rain

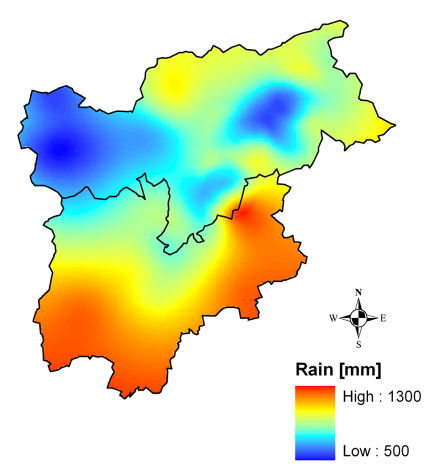

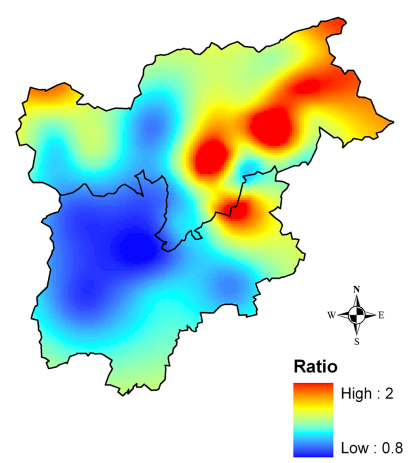

b) Summer/Fall contribution

Figure 5. Annual rainfall climatology and seasonal contribution. Average annual rainfall derived from available observations (a) and ratio of summer/fall contribution to annual rainfall (b). Note that available rain gauge observations were spatially interpolated using regularized spline technique to produce the spatial maps shown.

during fall season cannot be explained by the overall rainfall climatology and should be therefore attributed to other factors like antecedent wetness conditions (i.e., being wetter in the fall) and/or to the interactions between hydrogeomorphologic conditions and rainfall event properties.

A further step in the seasonal analysis of DF is related to the seasonality of DF rainfall properties. Figure 6 reports the distribution (as box plots) of DF rainfall accumulation and duration for the summer and fall seasons. The sample size for the DF cases of winter and spring (see Table 2) is considered rather limited (number of DF $<50$ ), to be able to derive statistical properties of the underlying distribution with an adequate degree of robustness, and therefore results for these cases were omitted. Results show that rainfall characteristics of DF-triggering events are significantly different between summer and fall season. Events during the summer are associated with lower rainfall accumulation and shorter duration while during the fall events are characterized by higher accumulations and longer durations. Specifically, average rainfall accumulation (duration) for summer events is equal to $44 \mathrm{~mm}$ ( $48 \mathrm{~h}$ ), while for fall events it is equal to $128 \mathrm{~mm}$ $(98 \mathrm{~h})$. These results are in agreement with the explanation provided above regarding events of convective nature dominating summer rainfall and frontal systems associated with long-lived widespread systems occurring in the fall season. Therefore, properties of DF-triggering rainfall events follow the general seasonal characteristics of rainfall events in the region without exhibiting any other particular pattern.

\subsection{Debris-flow distribution and weather circulation patterns}

Following the same methodological framework of Sect. 3.2, we examine in this section the relationship of DF occurrence and corresponding triggering rainfall properties, with the 

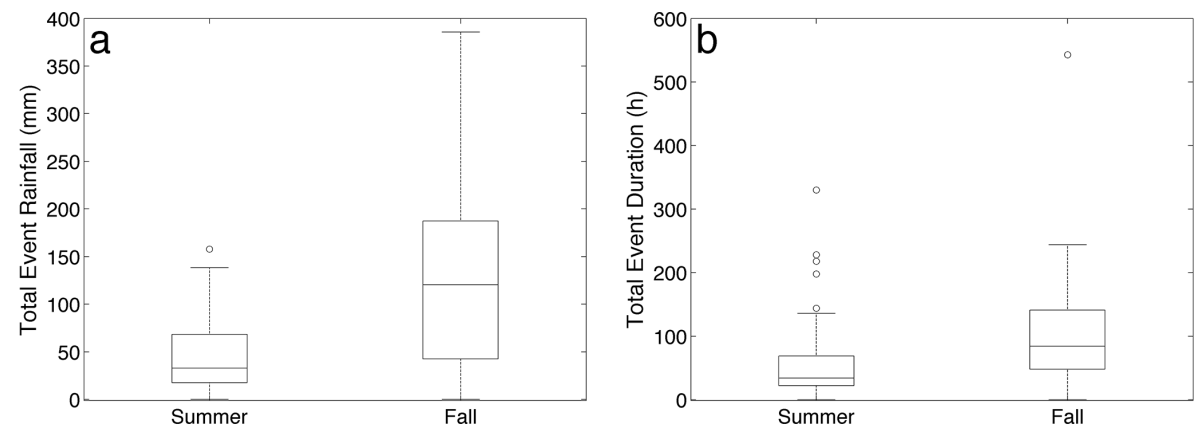

Figure 6. Box plots of DF rainfall accumulation (a) and duration (b) for summer and fall season. Circles correspond to outliers of the distribution (identified as greater that 1.5 times the inter-quartile range).

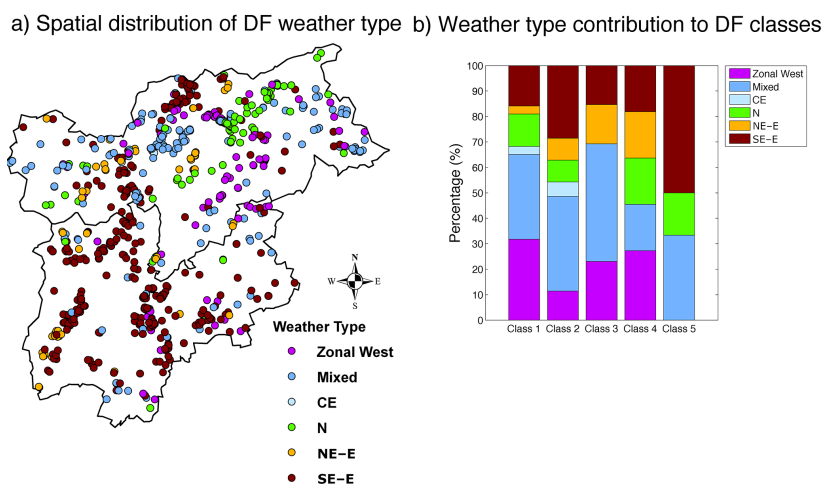

Figure 7. Weather type dependence of DF occurrence: (a) map showing spatial distribution of DF locations color coded according to weather type group, (b) correspondence between weather type and percentage of DF rainfall events, classified according to number of triggered DF. See Sect. 3.2 for definition of classes.

weather circulation patterns. As it may be observed in Fig. 7, weather circulation patterns corresponding to mixed, zonal west and meridional southeast and south (SE-E) groups dominate DF occurrence in the region. In addition, visual inspection of Fig. 7a reveals the clustering (i.e., geographical preference) of specific types. For example, the southern part of the study regions is associated with the SE-E group, while the northwest and central east is associated with mixed and zonal west groups. Results regarding the connection between weather type and the different classes of rainfall events (see Sect. 3.2) are reported in Fig. 7b. Again, results show clearly that zonal west, mixed and SE-E circulation patterns are the most dominant ones, with meridional north $(\mathrm{N})$ and northeast and east (NE-E) having an apparent, but significantly less percentage of occurrence. Although the number of events included in class 5 is only six, thus not permitting statistically significant interpretation of results; nevertheless, it is interesting to note that rainfall events that triggered the highest number of DF in the region and occurred during summer and fall season (see Fig. 4b) are predominantly associated with weather circulation patterns (50\% SE-E and $\sim 17 \% \mathrm{~N}$ ) that are much less frequent than mixed (which corresponds to $33 \%)$ and zonal west ( $0 \%$ occurrence) according to the climatology presented in Fig. 2.

Examination of rainfall characteristics as a function of the weather circulation patterns (Fig. 8) shows the variability of both rainfall accumulation and duration with weather type. Note that due to sample size limitations, results in Fig. 8 are presented for the four most dominant weather type groups. On average, accumulation and duration increases consistently moving from zonal west $(38 \mathrm{~mm}, 42 \mathrm{~h})$ and mixed ( $37 \mathrm{~mm}, 42 \mathrm{~h}$ ), to $\mathrm{N}(75 \mathrm{~mm}, 59 \mathrm{~h})$, to SE-E (128 mm, $99 \mathrm{~h})$. These results reflect at a large degree the effect on rainfall distribution due to the interaction between atmospheric circulation and orographic patterns in the region. For example, results on highest rainfall class agree with our general understanding on the intensification of rainfall in the region when southerly flows lift warm and moist air from the Mediterranean Sea over the Alps.

\subsection{DF rainfall thresholds}

Results obtained from previous sections revealed strong dependencies between DF-triggering rainfall properties with (a) season and (b) weather circulation patterns. This allow us to hypothesize that there is potential merit in classifying DF events according to these factors and identifying the DF rainfall thresholds separately for each case. In this section, we investigate and present results regarding the degree of variability of rainfall thresholds per case. Note that given that the focus of this work is on climatic characteristics of DF events, we only present results regarding the variability of rainfall thresholds to season and weather circulation patterns without evaluating the efficiency of these thresholds as a predictor.

Rainfall thresholds, used for predicting possible debrisflow occurrence, identify critical rainfall condition by linking rainfall intensity (or accumulation) and duration (for a review see Guzzetti et al., 2007, 2008). In this study, we considered a widely used model for the definition of the rainfall 

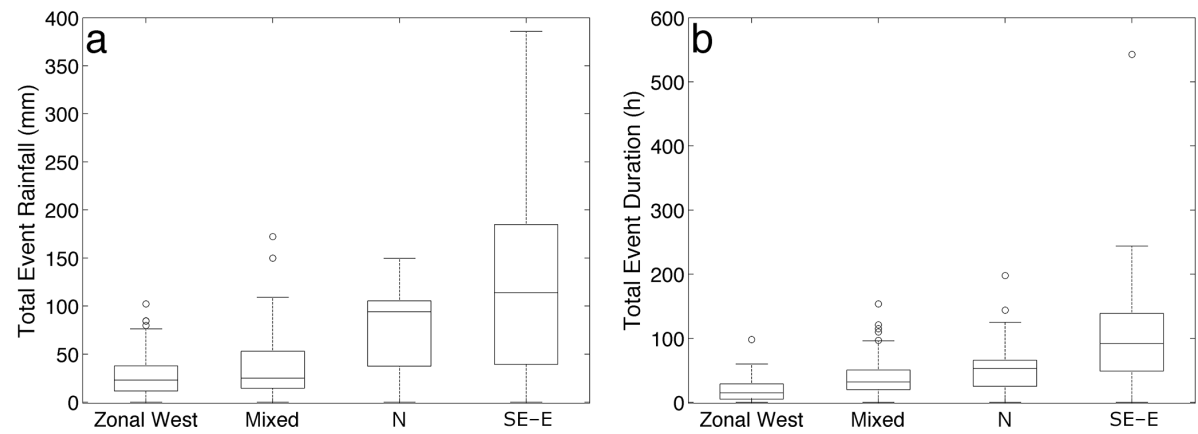

Figure 8. Box-plots of DF rainfall accumulation (a) and duration (b) of DF events associated with zonal west, mixed, meridional north and meridional southeast and south weather type groups (Table 1). Circles correspond to outliers of the distribution (identified as greater that 1.5 times the inter-quartile range).

thresholds, which is the intensity-duration $(I-D)$ threshold commonly adopting the power-law form

$I=\alpha D^{-\beta}$,

where $I\left(\mathrm{~mm} \mathrm{~h}^{-1}\right)$ is the mean intensity and $D(\mathrm{~h})$ is the duration of the DF-triggering rainfall. The multiplier $(\alpha)$ and exponent $(\beta)$ parameters are constants and are estimated by fitting the power-law model to the empirical data. For the estimation of parameters $\alpha$ and $\beta$, we applied the frequentist approach proposed by Brunetti et al. (2010). Note that the frequentist method allows identifying $I-D$ thresholds at different levels of exceedance probabilities (see for example Brunetti et al., 2010; Peruccacci et al., 2012). In this work, we adopted a $5 \%$ exceedance level, which means that the probability of a debris-flow-triggering rainfall event $(I-D$ pair) to be under the estimated $I-D$ threshold is less than $5 \%$.

To evaluate the significance of seasonal and weather type dependence of $I-D$ thresholds, we estimated the $I-D$ parameters from each DF sample corresponding to different season and weather circulation type. Note that in both cases, only the dominant seasons and weather types were examined. Also, $I-D$ pairs used for the estimation of thresholds were filtered to remove values associated with $I<1 \mathrm{~mm} \mathrm{~h}^{-1}$ and/or $D<2 \mathrm{~h}$, which are considered to fall within a range associated with high estimation uncertainty. Marra et al., 2014 has shown that using $I-D$ pairs below these thresholds may lead to unrealistic values of $I-D$ parameters. Filtering and splitting the original DF sample (821 data points) according to season and weather type group introduces uncertainty in the $I-D$ estimation procedure due to the size of individual samples considered. To account for this effect, we applied the methodology developed by Peruccacci et al. (2012). Specifically, for each case, $I-D$ estimation was repeated 1000 times on samples derived from the original population following the bootstrapping resampling technique (see Peruccacci et al., 2012 for more details). Results on the estimation of parameters $\alpha$ and $\beta$ and the uncertainty associated with sample size are summarized in Table 3 and are visualized in Fig. 9 (for different seasons) and Fig. 10 (for different weather types).

Several conclusions can be drawn from these results. The estimated $I-D$ parameters for summer and fall differ mainly on parameter $\alpha$, with $I-D$ for fall being associated with higher value. The sampling uncertainty appears significant mostly for the $\alpha$ parameter and is higher for fall. However, it can only partially explain the seasonal difference in parameter $\alpha$. Comparison of $I-D$ thresholds for different weather types shows that DF cases associated with meridional north pattern, are characterized by significantly higher (than in all other weather types) values of both $I-D$ parameters. Results for zonal west and mixed patterns are associated with very low values for parameter $\beta$ in comparison with the other cases, but also with reference to other thresholds reported in literature (see Guzzetti et al., 2007). Despite the associated uncertainties due to sampling size, overall the results presented (Table 3, Figs. 9 and 10) show that classification of DF according to season or weather type can lead to considerably different thresholds. Therefore, these findings suggest that such a classification-based approach could prove beneficial for the operational use of rainfall thresholds. However, quantification of the significance of improvement would require the comparison of such scheme (i.e., class-based $I-D$ ) with a static (i.e., independent of season and weather type) threshold.

\section{Conclusions}

In this work, the seasonal and atmospheric circulation patterns of debris flows in the eastern Italian Alps was examined. The study was focused on the Trentino-Alto Adige region and analysis was carried out over a 10-year (2000-2009) period, for which a unique catalog of debris-flow occurrences and hourly rain gauge precipitation was available. The principal conclusions derived are summarized below. 

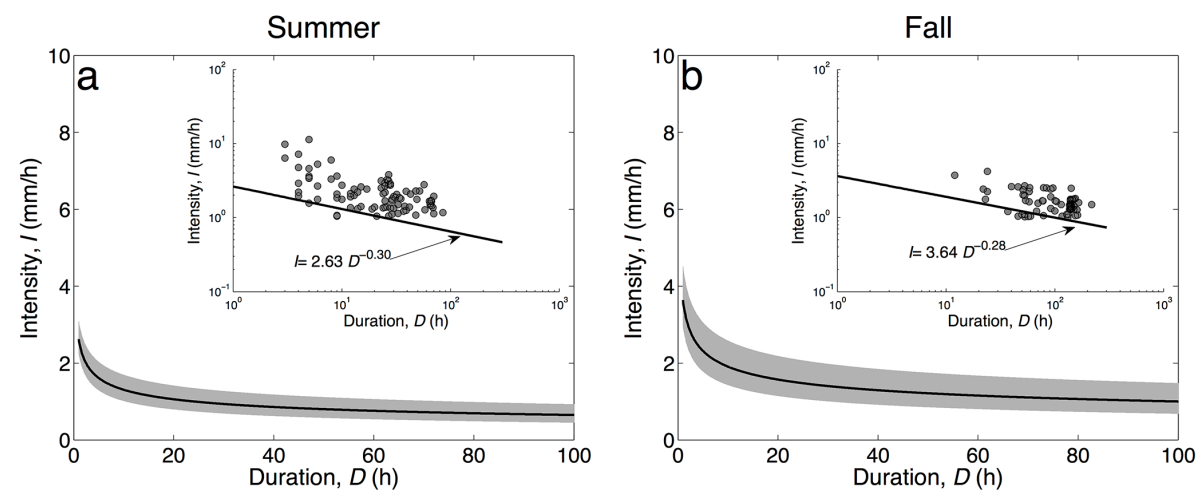

Figure 9. Intensity-duration thresholds estimated for (a) summer and (b) fall seasons. Black line corresponds to $I-D$ thresholds estimated from corresponding DF samples. Grey shade denotes the uncertainty bounds equal to the mean \pm 1 SD of the parameter values obtained from the resampling exercise (see Table 3).
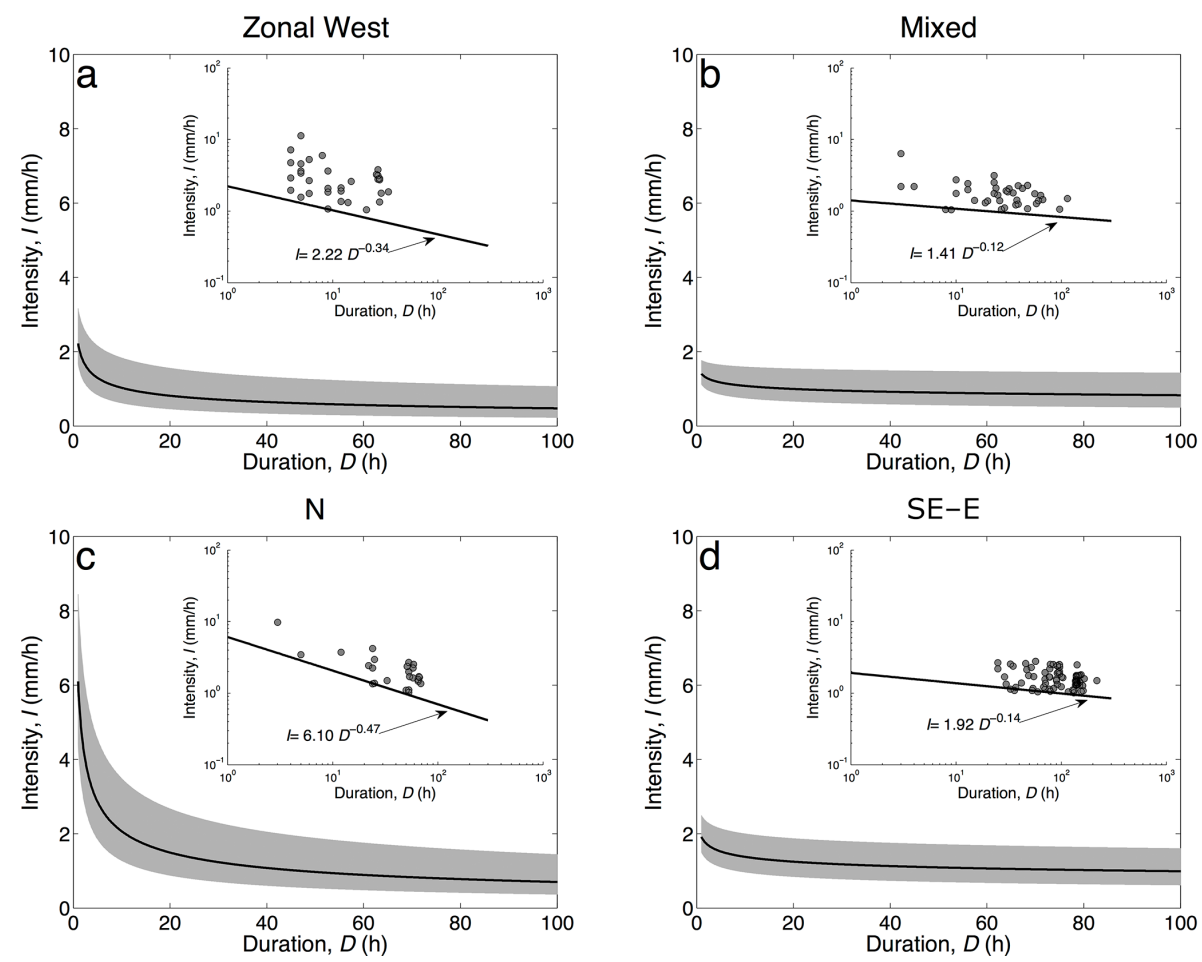

Figure 10. Intensity-duration thresholds estimated for (a) zonal west, (b) mixed, (c) meridional north and (d) meridional southeast and south weather type groups. Black line corresponds to $I-D$ thresholds estimated from corresponding DF samples. Grey shade denotes the uncertainty bounds equal to the mean $\pm 1 \mathrm{SD}$ of the parameter values obtained from the resampling exercise (see Table 3 ).

- The vast majority ( $92 \%$ ) of debris flows occur during summer and fall season. Furthermore, the two dominant seasons exhibit a clear geographical preference, with summer and fall season dominating the northern and southern part respectively. Analysis of these results with respect to the general rainfall climatology in the region showed that dominance of summer season in DF occurrence at the northeastern part is expected since it accounts for $50 \%$ of annual rainfall and contributes twice the rainfall relative to fall season. However, rainfall dur- ing summer and fall season at the southern part has equal contribution $(\sim 30 \%)$, which suggests that dominance of DF occurrence during fall season at the southern part is probably controlled by other rainfall properties and/or other variables (e.g. higher antecedent soil moisture).

- Rainfall properties (accumulation and duration) derived for each individual debris-flow location and from the closest available raingauge, exhibit a seasonal pattern 
Table 3. Estimated $I-D$ parameters $(\alpha, \beta)$ from original sample and their corresponding mean $(\mu)$ and $\operatorname{SD}(\sigma)$ derived from the resampling exercise.

\begin{tabular}{lrrrr}
\hline Season & $\alpha$ & $\mu_{\alpha}\left(\sigma_{\alpha}\right)$ & $\beta$ & $\mu_{\beta}\left(\sigma_{\beta}\right)$ \\
\hline Summer & 2.63 & $2.68(0.40)$ & 0.30 & $0.31(0.04)$ \\
Fall & 3.64 & $3.75(0.76)$ & 0.28 & $0.28(0.04)$ \\
\hline \multicolumn{5}{c}{ GWL group } \\
\hline Zonal west & 2.22 & $2.42(0.74)$ & 0.34 & $0.34(0.10)$ \\
Mixed & 1.41 & $1.45(0.32)$ & 0.12 & $0.11(0.06)$ \\
N & 6.10 & $6.43(2.01)$ & 0.47 & $0.46(0.08)$ \\
SE-E & 1.92 & $2.00(0.49)$ & 0.14 & $0.14(0.05)$ \\
\hline
\end{tabular}

as well. On average, summer events are associated with lower rainfall accumulation and shorter duration than fall events but with higher intensity. Essentially, this is a reflection of the general seasonal characteristics of rainfall in the region, where rainfall during summer is dominated by short duration convective systems, while during fall season widespread long-lived systems prevail (Borga et al., 2005).

- Weather circulation groups of mixed, zonal west and meridional southeast and south patterns dominate debris-flow occurrences in the region. Debris-flowtriggering rainfall properties vary considerably with weather type and specifically, both duration and accumulation increase on average moving from zonal west, to mixed, to $\mathrm{N}$ and finally to SE-E.

Variability of rainfall properties with season and weather type was further examined in the context of $I-D$ thresholds used for the prediction of debris-flow occurrence. Results revealed that there are indeed apparent differences in the $I-D$ thresholds estimated for each case (season or weather type). Although sampling size limitations introduce a considerable amount of uncertainty in the estimated thresholds, this alone cannot fully explain the observed differences. Therefore, results indicate that there is potentially merit in the application of a classification scheme (according to season and/or circulation type) on debris-flow event for potentially improving the accuracy of threshold-based prediction systems. However, as previously argued, evaluation of the performance of class-based thresholds would be required to determine the degree and potential significance of such an approach.

An important note that should be kept in mind when considering the results reported in this work regarding the derived rainfall properties and $I-D$ thresholds is that those depend on (a) the identification of individual rainfall events and (b) on the accuracy of rainfall estimates obtained from closest available gauges. Regarding the first point, we acknowledge that the use of an inter-event period of $24 \mathrm{~h}$ may not always represent well the properties of the debris-flow triggering storms, especially in the case of short rainstorms spaced by few hours, and can therefore impact at some degree the derived values. We adopted the $24 \mathrm{~h}$ threshold as a realistic value of a minimum period between consecutive events according to our experience and also following previous work (Nikolopoulos et al., 2014) to allow our results to be comparable with similar studies. However, more advanced procedures for the identification of triggering rainfall as recently proposed by Vessia et al. (2014) could be considered for further enhancing this type of analysis. On the second issue, which relates to the DF rainfall estimation from closest gauges, recent work on this topic (Nikolopoulos et al., 2014, Marra et al., 2014) has demonstrated clearly that gauge-based estimates of DF rainfall are largely underestimated, due to distance between closest gauge and DF location, and this results also in underestimation of $I-D$ thresholds. However, the current work focuses mostly on highlighting the relative differences of rainfall properties and subsequently of $I-D$ thresholds among different seasons/weather types and thus the absolute accuracy is not of focus. Therefore, we feel that the patterns portrayed regarding the seasonality and atmospheric circulation dependence hold despite the existence of bias in rainfall estimates.

Acknowledgements. This work is supported from EU FP7 Marie Curie Actions IEF project PIEF-GA-2011-302720 (HYLAND). We sincerely acknowledge Ripartizione Opere Idrauliche, and Servizio Bacini Montani, of the Autonomous Province of Bolzano and Trento (Italy), respectively, for providing access to the archive of debris flows and for discussion on the results. The rain gauge data used in this work were provided by Ufficio Idrografico (Bolzano) and Meteotrentino (Trento).

Edited by: F. Catani

Reviewed by: two anonymous referees

\section{References}

Borga, M., Vezzani, C. and Fontana, G. D.: Regional rainfall depthduration-frequency equations for an alpine region, Nat. Hazards, 36, 221-235, 2005.

Borga, M., Stoffel, M., Marchi, L., Marra, F., and Jakob, M.: Hydrogeomorphic response to extreme rainfall in headwater systems: Flash floods and debris flows, J. Hydrol., 518, 194-205, doi:10.1016/j.jhydrol.2014.05.022, 2014.

Brunetti, M. T., Peruccacci, S., Rossi, M., Luciani, S., Valigi, D., and Guzzetti, F.: Rainfall thresholds for the possible occurrence of landslides in Italy, Nat. Hazards Earth Syst. Sci., 10, 447-458, doi:10.5194/nhess-10-447-2010, 2010.

Dowling, C. and Santi, P.: Debris flows and their toll on human life: a global analysis of debris-flow fatalities from 1950 to 2011, NatHazards, 71, 203-227, doi:10.1007/s11069-013-0907-4, 2014.

Gestengabe, R. W. and Werner, P. C.: Katalog der Grosswetterlagen Europas (1881- 2004) Nach Paul Hess Und Helmut Brezowsky, 6: Verbesserte und Ergänzte Auflage, PIK Report No. 100, Potsdam Institut für Klimafolgenforschung, Potsdam, Germany, 153 pp., 2005 (in German). 
Govi, M., Mortara, G., and Sorzana, P. F.: Eventi idrologici e frane, Geologia Applicata e Idrogeologia, 20, 359-375, 1985 (In Italian).

Guzzetti, F., Peruccacci, S., Rossi, M. and Stark, C. P.: Rainfall thresholds for the initiation of landslides in central and southern Europe, Meteorol. Atmos. Phy., 98, 239-267-267, doi:10.1007/s00703-007-0262-7, 2007.

Guzzetti, F., Peruccacci, S., Rossi, M., and Stark, C.: The rainfall intensity-duration control of shallow landslides and debris flows: an update, Landslides, 5, 3-17, doi:10.1007/s10346-007-0112-1, 2008.

Hess, P. and Brezowsky, H.:Katalog der Grosswetterlagen Europas, Berichte des Deutschen Wetterdienstes in der US-Zone, Offenbach am Main, Germany, 33, 1952.

Hess, P. and Brezowsky, H.: Katalog der Grosswetterlagen Europas, 2. Auflage, Berichte des Deutschen Wetterdienstes, Offenbach am Main, Germany, 113, 1969.

Hess, P. and Brezowsky, H.: Katalog der Grosswetterlagen Europas 1881-1976, 3. Auflgae, Berichte des Deutschen Wetterdienstes, Offenbach am Main, Germany, 113, 1977.

James, P. M.: An objective classification method for Hess and Brezowsky Grosswetterlagen over Europe, Theor. Appl. Climatol., 88, 17-42, doi:10.1007/s00704-006-0239-3, 2007.

Kyselý, J. and Huth, R.: Changes in atmospheric circulation over Europe detected by objective and subjective methods, Theor. Appl. Climatol., 85, 19-36, doi:10.1007/s00704-005-0164-x, 2006.

Marra, F., Nikolopoulos, E. I., Creutin, J.-D., and Borga, M.: Radar rainfall estimation for the identification of debrisflow occurrence thresholds, J. Hydrol., 519, 1607-1619, doi:10.1016/j.jhydrol.2014.09.039, 2014.

Mei, Y., Anagnostou, E. N., Nikolopoulos, E. I., and Borga, M.: Error Analysis of Satellite Precipitation Products in Mountainous Basins, J. Hydrometeor., 15, 1778-1793, doi:10.1175/JHM-D13-0194.1, 2014.

Nikolopoulos, E. I., Crema, S., Marchi, L., Marra, F., Guzzetti, F., and Borga, M.: Impact of uncertainty in rainfall estimation on the identification of rainfall thresholds for debris flow occurrence, Geomorphology, 221, 286-297, doi:10.1016/j.geomorph.2014.06.015, 2014.

Norbiato, D., Borga, M., Merz, R., Blöschl, G., and Carton, A.: Controls on event runoff coefficients in the eastern Italian Alps, J. Hydrol., 375, 312-325, doi:10.1016/j.jhydrol.2009.06.044, 2009.

Parajka, J., Kohnová, S., Bálint, G., Barbuc, M., Borga, M., Claps, P., Cheval, S., Dumitrescu, A., Gaume, E., Hlavčová, K., Merz, R., Pfaundler, M., Stancalie, G., Szolgay, J., and Bloschl, G.: Seasonal characteristics of flood regimes across the Alpine Carpathian range, J. Hydrol., 394, 78-89, doi:10.1016/j.jhydrol.2010.05.015, 2010.
Peruccacci, S., Brunetti, M. T., Luciani, S., Vennari, C., and Guzzetti, F.: Lithological and seasonal control on rainfall thresholds for the possible initiation of landslides in central Italy, Geomorphology, 139-140, 79-90, doi:10.1016/j.geomorph.2011.10.005, 2012.

Petley, D.: Global patterns of loss of life from landslides, Geology, 40, 927-930, doi:10.1130/G33217.1, 2012.

Planchon, O., Quénol, H., Dupont, N., and Corgne, S.: Application of the Hess-Brezowsky classification to the identification of weather patterns causing heavy winter rainfall in Brittany (France), Nat. Hazards Earth Syst. Sci., 9, 1161-1173, doi:10.5194/nhess-9-1161-2009, 2009.

Salvati, P., Bianchi, C., Rossi, M., and Guzzetti, F.: Societal landslide and flood risk in Italy, Nat. Hazards Earth Syst. Sci., 10, 465-483, doi:10.5194/nhess-10-465-2010, 2010.

Schneuwly-Bollschweiler, M. and Stoffel, M.: Hydrometeorological triggers of periglacial debris flows in the Zermatt valley (Switzerland) since 1864, J. Geophys. Res., 117, F02033, doi:10.1029/2011JF002262, 2012.

Segoni, S., Rossi, G., Rosi, A., and Catani, F.: Landslides triggered by rainfall: A semi-automated procedure to define consistent intensity-duration thresholds, Comput. Geosci., 63, 123131, 2014.

Stoffel, M., Tiranti, D., and Huggel, C.: Climate change impacts on mass movements - Case studies from the European Alps, Sci. Total Environ., 493, 1255-1266, doi:10.1016/j.scitotenv.2014.02.102, 2014.

Toreti, A., Schneuwly-Bollschweiler, M., Stoffel, M., and Luterbacher, J.: Atmospheric Forcing of Debris Flows in the Southern Swiss Alps, J. Appl. Meteor. Climatol., 52, 1554-1560, doi:10.1175/JAMC-D-13-077.1, 2013.

Turkington, T., Ettema, J., van Westen, C. J., and Breinl, K.: Empirical atmospheric thresholds for debris flows and flash floods in the southern French Alps, Nat. Hazards Earth Syst. Sci., 14, 1517-1530, doi:10.5194/nhess-14-1517-2014, 2014.

Vennari, C., Gariano, S. L., Antronico, L., Brunetti, M. T., Iovine, G., Peruccacci, S., Terranova, O., and Guzzetti, F.: Rainfall thresholds for shallow landslide occurrence in Calabria, southern Italy, Nat. Hazards Earth Syst. Sci., 14, 317-330, doi:10.5194/nhess-14-317-2014, 2014.

Vessia, G., Parise, M., Brunetti, M. T., Peruccacci, S., Rossi, M., Vennari, C., and Guzzetti, F.: Automated reconstruction of rainfall events responsible for shallow landslides, Nat. Hazards Earth Syst. Sci., 14, 2399-2408, doi:10.5194/nhess-14-23992014, 2014 